\title{
A narrative review: has regionalization truly achieved its intended goal in the surgical management of pancreatic cancer?
}

\author{
Alexandra W. Acher ${ }^{1}$, Sharon M. Weber ${ }^{1}$, Timothy M. Pawlik ${ }^{2}$ \\ ${ }^{1}$ Division of Surgical Oncology, Department of Surgery, University of Wisconsin School of Medicine and Public Health, Madison, WI, USA; \\ ${ }^{2}$ Division of Surgical Oncology, Department of General Surgery, The Ohio State University College of Medicine, Columbus, OH, USA \\ Contributions: (I) Conception and design: All authors; (II) Administrative support: None; (III) Provision of study materials or patients: None; (IV) \\ Collection and assembly of data: AW Acher; (V) Data analysis and interpretation: All authors; (VI) Manuscript writing: All authors; (VII) Final \\ approval of manuscript: All authors. \\ Correspondence to: Timothy M. Pawlik, MD, MPH, PhD. Division of Surgical Oncology, Department of General Surgery, The Ohio State University \\ College of Medicine, 395 W 12th Ave, Columbus, OH 43210, USA. Email: Tim.Pawlik@osumc.edu.
}

\begin{abstract}
Objective: The purpose of this narrative review is to present the data to date on the volume-outcome association in pancreas cancer surgery and describe the prevalence of and barriers to regionalized pancreas cancer care in western health systems.

Background: Numerous studies have demonstrated an association between increasing hospital or surgeon volume and improved patient morbidity and mortality in patients undergoing surgery for pancreas cancer. However, since the initial promotion of minimum volume standards, regionalization has remained difficult to establish.

Methods: A PubMed literature search for years 1995-2020 was conducted to target original research on the volume-outcome association in pancreas cancer and the prevalence of associated regionalized care systems. Peer reviewed original research studies were selected based on their study design and potential to inform meaningful conclusions from the data.

Conclusions: Increasing hospital or surgeon volume is associated with improved short and long-term survival in pancreas cancer patients undergoing surgical resection. Despite the knowledge that increasing hospital and surgeon volume is associated with improved operative mortality and long term survival in pancreas cancer, the majority of patients undergo surgery at low volume hospitals with low volume surgeons. Barriers to regionalization are complex and involve the interaction of many conflicting factors and processes on human, health system, and national levels. Better understanding of the barriers to regionalization in pancreas cancer care is needed before this model of care becomes feasible.
\end{abstract}

Keywords: Regionalization; pancreas; cancer; outcomes

Submitted May 01, 2021. Accepted for publication Jul 06, 2021.

doi: $10.21037 /$ cco-21-54

View this article at: https://dx.doi.org/10.21037/cco-21-54

\section{Introduction}

The inverse relationship between hospital or surgeon volume and patient outcomes was first demonstrated in the late 1990s and early 2000s $(1,2)$. These studies demonstrated that increasing surgeon or hospital volume was associated with decreased operative mortality in patients undergoing complex surgery. Sub-analyses were performed by surgerytype and relative to other complex surgeries, pancreas resections demonstrated the strongest association between increasing volume and decreasing operative mortality $(1,2)$. Since these initial studies, a large amount of research has demonstrated an inverse relationship between hospital or surgeon volume and perioperative mortality and long-term survival in pancreas cancer patients (1-9).

Based on this cumulative evidence, many institutions and organizations have advocated for the consolidation of 
pancreas cancer surgery to high volume hospitals. This has manifested most publically through publication of LeapFrog minimum volume standards and promotion of the "Take the Volume Pledge" campaign by several prominent academic centers $(10,11)$. However, despite these promotional efforts and consistent evidence supporting the volume-outcome association in pancreas cancer treatment, most western health care systems have not transitioned to regionalized care models (12). In fact, most pancreas cancer surgery conducted in western health systems is performed in low volume hospitals by low volume surgeons (12-14).

The following review will focus on describing the literature to date on the volume-outcome association in pancreas cancer surgery, the distribution of care in current western health systems, and barriers to establishing regionalized care models in pancreas cancer. We present the following article in accordance with the Narrative Review reporting checklist (available at https://dx.doi.org/10.21037/ cco-21-54).

\section{Methods}

Given the nature of this research, this study was exempt from Institutional Review Board approval. A PubMed literature search was conducted for years 1995-2020 with combinations of the following search criteria: (((pancreatic OR pancreas) AND (cancer[tiab] OR neoplasm[tiab] OR tumor[tiab] OR tumour[tiab] OR malignanc*)) OR "Pancreatic Neoplasms" [MeSH] AND regionalization AND (outcome OR survival OR mortality[tiab] OR morbidity[tiab] OR [death]) AND volume AND (english[Filter])) NOT ((( pancreatic OR pancreas) AND (cancer[tiab] OR neoplasm[tiab] OR tumor[tiab] OR tumour[tiab] OR malignanc*)) OR "Pancreatic Neoplasms" [MeSH] AND (outcome OR survival OR mortality[tiab] OR morbidity[tiab] OR death[tiab] OR "Hospital Mortality" [Mesh]) AND volume AND (region* OR center[tiab] OR multicenter[tiab]) AND (english[Filter])) AND (english[Filter])).

Peer reviewed original research studies were selected for critical review. Studies were prioritized for inclusion based on study design and their potential to inform meaningful conclusions from the data. The authors are accountable for all aspects of the work in ensuring that questions related to the accuracy or integrity of any part of the work are appropriately investigated and resolved.

\section{Discussion}

\section{The volume-outcome association in pancreas cancer surgery}

The association between increasing volume and improved patient outcomes has been demonstrated for both hospital and surgeon volume. Specifically, high volume hospitals have a significantly decreased odds of operative mortality compared to low volume hospitals performing pancreas resections (OR 0.2, 95\% CI: 0.14-0.29) (1). Although the definitions of high volume hospital varies greatly by study, in general, the higher the minimum volume standard, the more pronounced the associated decrease in risk of operative mortality. For example, increasing the definition of high volume pancreatic surgery from $\geq 19$ pancreas resections/year to $\geq 30 /$ year was associated with a 2 -fold decreased odds of mortality (4). Although the volume-outcome association is most apparent with an increasing cutoff for high volume, this relationship has been demonstrated even in studies that defined high volume as anywhere from $\geq 2$ to $\geq 10$ pancreas resections per year (4).

Analyses examining surgeon volume have demonstrated similar results and trends. Risk-adjusted mortality models demonstrate a major increase in operative mortality associated with low volume surgeons $(7-15 \%$ operative mortality in low volume surgeons vs. $2-5 \%$ in high volume surgeons, hazard ratio $0.49,95 \%$ CI: $0.28-0.83)(2,15)$. Importantly, the definition of high surgeon volume in available studies varies greatly; however, in general, the higher the cutoff for surgeon case volume, the more pronounced the associated difference in mortality between high and low volume surgeons (6). There is a potential confounding relationship between hospital and surgeon volume as high volume surgeons tend to operate at high volume hospitals. However, the individual impacts of surgeon versus hospital volume are unclear; multiple studies demonstrate conflicting results regarding whether surgeon or hospital volume is more strongly associated with the volume-outcome effect $(2,16,17)$.

Patient undergoing pancreas cancer resections also have associated long-term survival benefits compared to patients undergoing resection at low volume hospitals. When considering all patients, 5 -year overall survival is $3 \%$ higher at high versus low volume hospitals $(15 \%$ vs. $12 \%$, respectively, $\mathrm{P}<0.05$ ); and when excluding operative or perioperative deaths, 5 -year conditional survival is 
higher among patients undergoing pancreas cancer resection at high versus low volume hospitals (16\% vs. $13 \%$, respectively, $\mathrm{P}<0.05)(7)$. In reality, these differences equate to avoidance of perioperative death in an estimated 225 patients per year and avoidance of long-term death in 491 patients per year through the consolidation of pancreas cancer surgery to high volume centers (7).

These cumulative data demonstrate a strong association between hospital or surgeon volume and improved short and long-term survival. However, despite these relationships and the public campaigns to promote regionalized care models, most western health systems continue to function through individual rather than centralized cancer care systems.

\section{Current distribution of care in pancreas cancer surgery}

Within the United States, only 7\% of hospitals meet LeapFrog criteria for high volume while $89 \%$ are considered low volume based on their yearly operative census data (14). The relatively few high volume hospitals provide pancreas cancer surgical care to $42 \%$ of pancreas cancer patients while the more prevalent low volume hospitals provide care to $47 \%$ of pancreas cancer patients (14). Similarly, $82 \%$ of surgeons performing pancreas cancer surgery in the United States perform $\leq 2$ pancreas resections per year while only $5 \%$ perform $\geq 12$ pancreas resections per year (13). In Europe, the prevalence of regionalized pancreas care models vary by country but overall, the majority of patients receive pancreas cancer surgery with low volume surgeons in small volume hospitals (12). Countries with more prominent governmental presence and single payor health care systems are able to transition more easily to centralized models; however, this is feasible in a very select minority of countries (12). Despite general acceptance of the volumeoutcome association across Europe, most countries maintain non-centralized pancreas cancer care models (12).

Despite the association between volume and patient outcomes and the intentions of the promotion of regionalized pancreas cancer programs, most patients undergoing surgery for pancreas cancer do so in hospitals that do not meet criteria for high volume. Lack of evolution toward regionalized care models in western health systems likely reflects the interaction of many complex patient, hospital system, and national contexts and priorities.

\section{Barriers to regionalized care in pancreas cancer}

The barriers to regionalized pancreas cancer in western health systems are significant and reflect the interplay of many conflicting and nuanced factors and processes. Most fundamentally, countries without single-payor health care systems or flexible insurance coverage policies face significant barriers to adopting regionalized cancer care models (18-22). Without fundamental change to the relationship between patient, hospital system, and health insurance coverage, regionalized cancer care will remain unfeasible (18-22).

Since the initial promotion of minimum-volume standards in pancreas cancer surgery, many have argued that regionalized care would only worsen already existing disparities in access to pancreas cancer treatment. Regionalization does not solve and actually may worsen existing disparities in access to pancreas cancer care faced by patients disadvantaged by rurality, race, or socioeconomic status (18-22). Instead, regionalization may offer further benefits to patients who are most advantaged in western health care systems - those who are white, wealthy, and urban (18-22).

Additionally, although the intentions of minimum volume standards are to optimize care for patients with pancreas cancer, this does not necessarily equate to a more patient-centered model of care. Patients have identified a clear preference to receive care without exorbitant travel expectations, and even a willingness to accept increased postoperative morbidity and mortality risk if it means they can receive care locally (23). Arguably, a truly patientcentered health care system, one which seeks to increase optimized care for all patients, should prioritize access to high quality care at all hospitals, regardless of their size or location. In particular, centralization of complex surgical care has been accomplished successfully in several countries. For example, centralization of pancreatic surgery was successful and has resulted in improved clinical outcomes in the western part of the Netherlands, demonstrating the effectiveness of centralization (24). A different study from the Netherlands similarly noted that centralization of pancreatic cancer surgery led to increased resection rates and high-volume centers had significantly better survival rates (25). In Germany, patients who are undergoing major pancreatic resections similarly have improved outcomes if they are admitted to higher volume hospitals (26). However, 
current health policies fail to centralize pancreatic surgery procedures in Germany, and therefore new strategies to initiate a sufficient centralization process in the field of pancreatic surgery are needed. Unfortunately, Polonski et al. noted that most European countries have so far failed to establish centralization of pancreatic surgery to highvolume centers due to numerous reasons (12). Considering a plateau in survival rates of patients undergoing treatment for pancreatic cancer in Europe during the last 15 years, the authors argued that the data further emphasized the need for centralization of pancreatic surgery. The lack of routine and coordinated centralization of complex surgical cases such as pancreatic resection also characterize care in North and South America, as well as Asia.

\section{Summary}

Despite consistent evidence that increasing hospital or surgeon volume is associated with improved perioperative morality and long-term survival, most patients continue to receive care in low volume hospitals by low volume surgeons. The etiology of this discrepancy is complex and reflects the interaction of many conflicting and nuanced factors and processes. The goal of regionalized care in pancreas cancer is to increase patient access to optimized surgical treatment, however, given the barriers to a regionalized model, this goal remains relatively difficult to achieve. Further research should focus on understanding the social, political, and economic barriers to this model of care within western health care systems. Until these barriers are better understood and mitigated, it will remain difficult to build functional regionalized cancer care models for pancreas cancer treatment.

\section{Acknowledgments}

Funding: None.

\section{Footnote}

Provenance and Peer Review: This article was commissioned by the Guest Editor (Savio George Barreto) for the series "Unresolved Issues in Pancreatic Cancer" published in Chinese Clinical Oncology. The article has undergone external peer review.

Reporting Checklist: The authors have completed the Narrative Review reporting checklist. Available at https:// dx.doi.org/10.21037/cco-21-54

Conflicts of Interest: All authors have completed the ICMJE uniform disclosure form (available at https://dx.doi. org/10.21037/cco-21-54). The series "Unresolved Issues in Pancreatic Cancer" was commissioned by the editorial office without any funding or sponsorship. The authors have no other conflicts of interest to declare.

Ethical Statement: The authors are accountable for all aspects of the work in ensuring that questions related to the accuracy or integrity of any part of the work are appropriately investigated and resolved.

Open Access Statement: This is an Open Access article distributed in accordance with the Creative Commons Attribution-NonCommercial-NoDerivs 4.0 International License (CC BY-NC-ND 4.0), which permits the noncommercial replication and distribution of the article with the strict proviso that no changes or edits are made and the original work is properly cited (including links to both the formal publication through the relevant DOI and the license). See: https://creativecommons.org/licenses/by-nc-nd/4.0/.

\section{References}

1. Birkmeyer JD, Siewers AE, Finlayson EV, et al. Hospital volume and surgical mortality in the United States. N Engl J Med 2002;346:1128-37.

2. Birkmeyer JD, Stukel TA, Siewers AE, et al. Surgeon volume and operative mortality in the United States. N Engl J Med 2003;349:2117-27.

3. van Heek NT, Kuhlmann KF, Scholten RJ, et al. Hospital volume and mortality after pancreatic resection: a systematic review and an evaluation of intervention in the Netherlands. Ann Surg 2005;242:781-8, discussion 788-90.

4. Hata T, Motoi F, Ishida M, et al. Effect of Hospital Volume on Surgical Outcomes After Pancreaticoduodenectomy: A Systematic Review and Meta-analysis. Ann Surg 2016;263:664-72.

5. Pecorelli N, Balzano G, Capretti G, et al. Effect of surgeon volume on outcome following pancreaticoduodenectomy in a high-volume hospital. J Gastrointest Surg 2012;16:518-23.

6. Macedo FIB, Jayanthi P, Mowzoon M, et al. The Impact of Surgeon Volume on Outcomes After Pancreaticoduodenectomy: a Meta-analysis. J Gastrointest 
Surg 2017;21:1723-31.

7. Bilimoria KY, Bentrem DJ, Feinglass JM, et al. Directing surgical quality improvement initiatives: comparison of perioperative mortality and long-term survival for cancer surgery. J Clin Oncol 2008;26:4626-33.

8. La Torre M, Nigri G, Ferrari L, et al. Hospital volume, margin status, and long-term survival after pancreaticoduodenectomy for pancreatic adenocarcinoma. Am Surg 2012;78:225-9.

9. Bilimoria KY, Talamonti MS, Sener SF, et al. Effect of hospital volume on margin status after pancreaticoduodenectomy for cancer. J Am Coll Surg 2008;207:510-9.

10. Urbach DR. Pledging to Eliminate Low-Volume Surgery. N Engl J Med 2015;373:1388-90.

11. LeapFrog. LeapFrog Ambulatory Surgery Center Survey. 2020. Available online: https://www.leapfroggroup.org/ sites/default/files/Files/Leapfrog\%20Report\%20on\%20 Safe\%20Surgical\%20Volumes\%202020.pdf

12. Polonski A, Izbicki JR, Uzunoglu FG. Centralization of Pancreatic Surgery in Europe. J Gastrointest Surg 2019;23:2081-92.

13. Sheetz KH, Nuliyalu U, Nathan H, et al. Association of Surgeon Case Numbers of Pancreaticoduodenectomies vs Related Procedures With Patient Outcomes to Inform Volume-Based Credentialing. JAMA Netw Open 2020;3:e203850.

14. Jacobs RC, Groth S, Farjah F, et al. Potential Impact of "Take the Volume Pledge" on Access and Outcomes for Gastrointestinal Cancer Surgery. Ann Surg 2019;270:1079-89.

15. Eppsteiner RW, Csikesz NG, McPhee JT, et al. Surgeon volume impacts hospital mortality for pancreatic resection. Ann Surg 2009;249:635-40.

16. Nathan H, Cameron JL, Choti MA, et al. The volumeoutcomes effect in hepato-pancreato-biliary surgery: hospital versus surgeon contributions and specificity of the

Cite this article as: Acher AW, Weber SM, Pawlik TM. A narrative review: has regionalization truly achieved its intended goal in the surgical management of pancreatic cancer? Chin Clin Oncol 2021;10(5):46. doi: 10.21037/cco-21-54 relationship. J Am Coll Surg 2009;208:528-38.

17. Toomey PG, Teta AF, Patel KD, et al. High-volume surgeons vs high-volume hospitals: are best outcomes more due to who or where? Am J Surg 2016;211:59-63.

18. Wasif N, Etzioni DA. Regionalization of Complex Cancer Surgery: How, When, and Why? JAMA Netw Open 2018;1:e184586.

19. Walker BB, Schuurman N, Wen CK, et al. Cancer resection rates, socioeconomic deprivation, and geographical access to surgery among urban, suburban, and rural populations across Canada. PLoS One 2020;15:e0240444.

20. Raphael MJ, Siemens DR, Booth CM. Would Regionalization of Systemic Cancer Therapy Improve the Quality of Cancer Care? J Oncol Pract 2019;15:349-56.

21. Fong ZV, Loehrer AP, Fernandez-Del Castillo C, et al. Potential impact of a volume pledge on spatial access: A population-level analysis of patients undergoing pancreatectomy. Surgery 2017;162:203-10.

22. Stitzenberg KB, Sigurdson ER, Egleston BL, et al. Centralization of cancer surgery: implications for patient access to optimal care. J Clin Oncol 2009;27:4671-8.

23. Finlayson SR, Birkmeyer JD, Tosteson AN, et al. Patient preferences for location of care: implications for regionalization. Med Care 1999;37:204-9.

24. Gooiker GA, van der Geest LG, Wouters MW, et al. Quality improvement of pancreatic surgery by centralization in the western part of the Netherlands. Ann Surg Oncol 2011;18:1821-9.

25. Gooiker GA, Lemmens VE, Besselink MG, et al. Impact of centralization of pancreatic cancer surgery on resection rates and survival. Br J Surg 2014;101:1000-5.

26. Krautz C, Nimptsch U, Weber GF, et al. Effect of Hospital Volume on In-hospital Morbidity and Mortality Following Pancreatic Surgery in Germany. Ann Surg 2018;267:411-7. 